\title{
ESTIMATION OF THE NEW KEYNESIAN PHILLIPS CURVE IN THE CZECH ENVIRONMENT
}

\author{
Milan Bouda*
}

\section{Introduction}

In the last fifty years since Phillips (1958) first pointed to a possible relationship between unemployment and price and wage inflation, the Phillips curve has become one of the most intensely debated topics in macroeconomics. The recent interest in this relationship stems partly from the fact that more and more countries have adopted inflation targeting as their monetary policy regime. In recent research in open economy macroeconomics, New Keynesian Dynamic Stochastic General Equilibrium (DSGE) models have become increasingly popular. In fact, this school has been given its own name, New Open Economy Macroeconomics (NOEM). The New Keynesian Phillips curve (NKPC) is a key equation in these models, representing the supply side of the economy. The main feature of the NKPC is that it includes expected future inflation. Because of rigidities in price adjustment, firms will base their current pricing decisions on what they expect about the future. There have been two main approaches to estimating the NKPC in the literature. The first approach uses single equation methods where one estimates the curve as an isolated relationship. The second approach estimates the curve as part of a fully specified model. Results from single equation methods include Galí and Gertler (1999) and Galí, Gertler and López-Salido (2001), who claim that a hybrid New Keynesian Phillips curve, including both expected future inflation and lagged inflation, explains well the inflationary process in the US and the EU economy. They estimate different versions of the curve using the General Method of Moments (GMM) and find that the purely forward-looking version is rejected. The backward-looking term is significant, although not very important. By contrast, Fuhrer (1997), finds that expected future inflation is unimportant in explaining price inflation in the US. Smets and Wouters (2003) use Bayesian Maximum Likelihood to estimate the NKPC as part of a fully specified DSGE model. They use data from the Euro area and find that expected future inflation is dominant, but also that lagged inflation plays an important role. Adolfson et al. (2007) use the same method as Smets and Wouters (2003), but on an open economy DSGE model. They use data for the Euro area as well, and their results coincide with the ones in Smets and Wouters (2003): expected future inflation seems to be dominant. In this paper, I will focus on the New Keynesian perspective and

\footnotetext{
* University of Economics Prague, Faculty of Informatics and Statistics; Česká spořitelna, a.s. (bouda.mil@ seznam.cz).

This paper is supported by funding of IGA VŠE, project IG403052.
} 
take the model from Gali and Monacelli (2004), which describes a simple DSGE model for a small open economy with nominal rigidities. One of the key equations in this model is the NKPC, representing the supply side of the economy. The main difference between the NKPC and the original Phillips curve is that the NKPC is forward-looking: current inflation depends on the expectation of future inflation. Another difference is that in the NKPC, the driving variable in the inflation process is real marginal costs, not unemployment. The main goal of the paper is to replicate the model formulated by Galí and Monacelli (2004) and estimate the parameters of the NKPC in the Czech environment. The NKPC is estimated as part of a fully calibrated DSGE model of the Small Open Economy (SOE). Finally, the impact of all stochastic shocks on domestic and imported inflation is discussed.

\section{The New Keynesian Phillips curve}

The key assumption underlying the NKPC is that it is either costly, or in some way difficult, to adjust prices every period. This could be due to some kind of menu costs of changing prices. There have been several suggestions on how to model price rigidity. Taylor $(1979,1980)$ assumed that contracts are made for several periods at the time. Then, if only a fraction of prices and wages are changed every period, both the past and the expected future will play a role in optimal price and wage setting. Calvo (1983) assumed that firms are not able to change their prices every period, and that the probability that a firm is able to change its prices in a given period is determined by an exogenous Poisson process. In this case, the duration of prices will be random, and firms need to form expectations about the future to set optimal prices. Rotemberg (1982) assumes quadratic costs of changing prices. In this case, it may not be optimal to change prices to what is optimal as seen from the current period only, because the optimal price in the next period might be different, and then the cost of changing the prices could exceed the gain. Therefore, one has to form expectations of future optimal prices when setting prices today. Here, I will first focus on Rotemberg's assumption and assume that there exist costs of changing prices relative to both steady-state inflation and previous period aggregate inflation. Following Galí and Gertler (1999), I will also discuss a Calvo representation of the NKPC which assumes that some firms set prices according to a backward-looking rule of thumb. When we want to look at the economy of a Small Open Economy, we need to distinguish between domestic and imported inflation. Several empirical studies have rejected the law of one price, at least in the short run, see Campa and Goldberg (2005) and Goldberg and Knetter (1997) for details. In line with Smets and Wouters (2002), I assume that there is complete pass-through to import prices at the docks, but that the importers face adjustment costs in their own price setting, so that there will be incomplete pass-through to consumer prices of imported goods.

The domestic economy has two types of firms, domestic producers and importers, and a continuum of each type, indexed from zero to one. Domestic producers sell their products to domestic and foreign consumers while importers only sell their products on the domestic market. The SOE model is taken from Galí and Monacelli (2004) and the NKPC is taken from Galí et al. (2001). 
The consumption index is given by

$$
C_{t}=\left[(1-\alpha)^{\frac{1}{\eta}} C_{H, t}^{\frac{\eta-1}{\eta}}+\alpha^{\frac{1}{\eta}} C_{F, t}^{\frac{\eta-1}{\eta}}\right]^{\frac{\eta}{\eta-1}},
$$

where $\alpha$ is related to the degree of openness of the domestic economy. $C_{H, t}$ and $C_{F, t}$ represent aggregate consumption of domestic and foreign goods, given by

$$
C_{H, t}=\left[\int_{0}^{1} C_{H, t}(i)^{\frac{\varepsilon_{H, t}-1}{\varepsilon_{H, t}}} d i\right]^{\frac{\varepsilon_{H, t}}{\varepsilon_{H, t}-1}}
$$

and

$$
C_{F, t}=\left[\int_{0}^{1} C_{F, t}(i)^{\frac{\varepsilon_{F, t}-1}{\varepsilon_{F, t}}} d i\right]^{\frac{\varepsilon_{F, t}}{\varepsilon_{F, t}-1}},
$$

where both domestic and foreign goods are defined as CES aggregates of a continuum of differentiated goods, indexed by $i$. The elasticity of substitution between domestic and foreign goods is given by $\eta>0$, and the elasticities of substitution between the different types of domestic and foreign goods are given by $\varepsilon_{H}$ and $\varepsilon_{F}$, respectively. Optimal demand for each category of goods is

$$
C_{H, t}=(1-\alpha)\left(\frac{P_{H, t}}{P_{t}}\right)^{-\eta} C_{t}
$$

and

$$
C_{F, t}=(1-\alpha)\left(\frac{P_{F, t}}{P_{t}}\right)^{-\eta} C_{t},
$$

where

$$
P_{H, t}=\left[\int_{0}^{1} P_{H, t}(i)^{1-\varepsilon_{H, t}} d i\right]^{\frac{1}{\varepsilon_{H, t}-1}}
$$

and

$$
P_{F, t}=\left[\int_{0}^{1} P_{F, t}(i)^{1-\varepsilon_{F, t}} d i\right]^{\frac{1}{\varepsilon_{F, t}-1}}
$$

are the price indices of domestic and foreign goods, respectively. The aggregate price level, or the consumer price index (CPI), is

$$
P_{t} \equiv\left[(1-\alpha) P_{H, t}^{1-\eta}+\alpha P_{F, t}^{1-\eta}\right]^{\frac{1}{1-\eta}} .
$$


In the same way, we find optimal demand for each individual good within the two categories to be

$$
C_{H, t}(i)=\left(\frac{P_{H, t}(i)}{P_{H, t}}\right)^{-\varepsilon_{H, t}} C_{H, t}
$$

and

$$
C_{F, t}(i)=\left(\frac{P_{F, t}(i)}{P_{F, t}}\right)^{-\varepsilon_{F, t}} C_{F, t} .
$$

Domestic producers produce domestic goods by a constant return to scale technology defined by $Y_{t}(i)=Z_{t}^{Y} N_{t}(i)$, where labour, $N_{t}$, is the only input factor and $Z_{t}^{Y}$ is total factor productivity. $Z_{t}^{Y}$ is assumed to follow the process

$$
\ln \left(\frac{Z_{t}^{Y}}{Z^{Y}}\right)=\rho^{Y} \ln \left(\frac{Z_{t-1}^{Y}}{Z^{Y}}\right)+\varepsilon_{t}^{Y},
$$

where $\rho^{Y}\left(0 \leq \rho^{Y} \leq 1\right)$ measures the degree of persistence and $\varepsilon_{t}^{Y}$ is an i.i.d. shock. Throughout the thesis, a variable without a time subscript denotes the steady-state value of that variable. Domestic goods are sold to both domestic and foreign households and also to the domestic government. We assume that the law of one price holds in the foreign economy and that foreign consumers have identical preferences for domestic goods as domestic consumers. Foreign demand for domestic goods, $C_{H, t}^{f}$, is then

$$
C_{H, t}^{f}=\alpha^{f}\left(\frac{P_{H, t}}{S_{t} P_{F, t}^{f}}\right)^{-\eta} C_{t}^{f},
$$

where $C_{t}^{f}$ is total foreign demand. Total demand for domestic goods, $C_{H, t}^{T}$ becomes

$$
C_{H, t}^{T}=C_{H, t}+C_{H, t}^{f}+G_{t}=(1-\alpha)\left(\frac{P_{H, t}}{P_{t}}\right)^{-\eta} C_{t}+\alpha^{f}\left(\frac{P_{H, t}}{S_{t} P_{F, t}^{f}}\right)^{-\eta} C_{t}^{f}+G_{t},
$$

where the first term is domestic consumers' demand for domestic goods, the second term is foreign consumers' demand for domestic goods and the last term, $G$, denotes government spending.

In line with Rotemberg (1982) and Hunt and Rebucci (2005), I assume that the firms face quadratic costs of price adjustment. The costs arise both from changes in inflation relative to steady-state inflation and from changes in firm i's inflation relative to previous period aggregate inflation.

The monopolistic competition assumption is essential in New Keynesian modelling. It ensures that firms are willing to change output levels when demand changes, even if they do not change their prices. Importers buy the same input at a given world price. 
Each importer then puts a unique brand on it and sells the final product on the domestic market. The importers have monopoly power on the market for their own (branded) good.

If we log-linearise the first-order conditions around the steady state which are formulated by Hunt and Rebucci (2005), we get the log-linearised versions of the two NKPC for domestic and imported inflation assuming that all firms within the two sectors are equal

$$
\begin{aligned}
& \hat{\pi}_{t}^{H}=-\frac{\varepsilon_{H}}{\phi_{C_{H 1}}+(1+\beta) \phi_{C_{H 2}}} \hat{\varepsilon}_{H, t}+\frac{\varepsilon_{H}\left(\varepsilon_{H}-1\right)}{\phi_{C_{H 1}}+(1+\beta) \phi_{C_{H 2}}}\left(\hat{w}_{t}-\hat{Z}_{t}^{Y}-\hat{p}_{H, t}\right) \\
& +\frac{\phi_{C_{H 2}}}{\phi_{C_{H 1}}+(1+\beta) \phi_{C_{H 2}}} \hat{\pi}_{t-1}^{H}+\beta \frac{\phi_{C_{H 1}}+\phi_{C_{H 2}}}{\phi_{C_{H 1}}+(1+\beta) \phi_{C_{H 2}}} E_{t} \hat{\pi}_{t+1}^{H}, \\
& \hat{\pi}_{t}^{F}=-\frac{\varepsilon_{F}}{\phi_{C_{F 1}}+(1+\beta) \phi_{C_{F 2}}} \hat{\varepsilon}_{F, t}+\frac{\varepsilon_{F}\left(\varepsilon_{F}-1\right)}{\phi_{C_{F 1}}+(1+\beta) \phi_{C_{F 2}}}\left(\hat{Q}_{t}-\hat{p}_{F, t}\right) \\
& +\frac{\phi_{C_{F 2}}}{\phi_{C_{F 1}}+(1+\beta) \phi_{C_{F 2}}} \hat{\pi}_{t-1}^{H}+\beta \frac{\phi_{C_{F 1}}+\phi_{C_{F 2}}}{\phi_{C_{F 1}}+(1+\beta) \phi_{C_{F 2}}} E_{t} \hat{\pi}_{t+1}^{F} .
\end{aligned}
$$

All the variables with a hat are percentage deviations from the steady-state level of the corresponding variable. Small characters are real variables (divided by the price index, e.g., $p_{H}=P_{H} / P$ ). The inflation rates in the two prices are defined as $\pi_{t}^{i}=P_{t}^{i} / P_{t-1}^{i}$ and $Q$ is the real exchange rate, defined as $Q=S P_{F}^{f} / P . \beta$ is the discount factor. We see that inflation depends negatively on movements in the elasticity of demand between different types of goods. An increase in the elasticity means less market power for the firms and thus a lower mark-up. I therefore refer to $\hat{\varepsilon}$ as a shock to market power. We also see that if real marginal costs increase, the firm will increase its price. Depending on $\beta$ and the $\phi$ parameters, the coefficients on expected future inflation and lagged inflation can vary between zero and one. For a given discount factor $\beta$, the coefficient on lagged inflation must be between zero and one half. If there are no costs of adjusting inflation relative to steady-state inflation, that is, the $\phi_{1}$ are zero, then the coefficients on lagged inflation and expected future inflation reduce to $1 /(1+\beta)$ and $\beta /(1+\beta)$, respectively. This means that for $\beta$ close to unity, both coefficients will be approximately one half. By introducing costs of deviating from steady-state inflation, we see that we get a more flexible Phillips curve. By setting the $\phi_{2}$ to zero, corresponding to no costs of changing prices relative to past inflation, we get the purely forward-looking NKPC.

\section{The complete model}

This chapter outlines the demand side of the model. This is represented by both domestic and foreign households and the domestic government. Then we specify an interest rate rule for the central bank and the equilibrium of the economy. Households are repre- 
sented by a continuum of infinitely-lived individuals, indexed by $j$. These households consume domestic goods $C_{H}$ and imported goods $C_{F}$. The consumers maximise the following utility function

$$
E_{0} \sum_{t=0}^{\infty} \beta^{t}\left[\frac{\left(C_{t}^{j}-h C_{t-1}\right)^{1-\sigma}}{1-\sigma}-\frac{\left(N_{t+i}^{j}\right)^{1+\varphi}}{1+\varphi}\right],
$$

where $E_{0}$ is the conditional expectation operator, $\beta$ is the discount factor, $C_{t}^{j}$ is the consumption of household $j$ in time $t . C_{t-1}$ is the aggregate consumption in the previous period and habit persistence $0<h<1 . N_{t+1}^{j}$ is the labour input of individual household $j$ in the next period. Parameter $\sigma_{1}$ is the inverse elasticity of intertemporal substitution and $\varphi_{2}$ represents the Frisch elasticity of labour supply.

The utility function is maximised subject to the following budget constraint

$$
C_{t}^{j}+\frac{B_{t}^{j}}{\left(1+r_{t}\right) P_{t}}+\frac{S_{t} B_{t}^{f, j}}{\left(1+r_{t}^{f}\right) \Phi\left(A_{t}\right) P_{t}}=\frac{B_{t-1}^{j}}{P_{t}}+\frac{S_{t} B_{t-1}^{f, j}}{P_{t}}+\frac{W_{t}}{P_{t}} N_{t}^{j}+X_{t}^{j}-T_{t}^{j},
$$

where $B_{t}^{j}$ and $B_{t}^{f, j}$ are one-period bond holdings in the domestic and foreign currency respectively, $r_{t}$ and $r_{t}^{f}$ are domestic and foreign short nominal interest rates. $T$ is the lump sum tax. To ensure stationary bond holdings, we follow Benigno (2001) and add a risk premium on foreign bonds. The risk premium is represented by the function $\Phi\left(A_{t}\right)=e^{-\Phi A_{t}+Z_{t}^{B}} \quad$ which is strictly decreasing in the domestic economy's aggregate real holdings of föreign bonds defined as $A_{t} \equiv S_{t} B_{t}^{f} / P_{t}$. To account for uncertainty in the risk premium, we add the shock $Z^{B}$, which follows the AR1 process

$$
Z_{t}^{B}=\rho^{B} Z_{t-1}^{B}+\varepsilon_{t}^{B}
$$

where $\rho^{B}$ represents the degree of persistence and $\varepsilon_{t}^{B}$ is an i.i.d. ${ }^{3}$ shock. Even though the premium depends on bond holdings, the households treat it as a given when they optimise because their individual influence is negligible. Real profits in the economy are divided equally among all households. This yields the lump sum term $X_{t}^{j}$ in the budget constraint.

Households receive all profits from domestic firms and importers. The households also receive all revenue from price adjustment costs. It is assumed that foreigners do

1 The elasticity of intertemporal substitution measures the consumer's willingness to shift consumption between periods. When this elasticity is low, the consumers are said to be risk-averse. Thus, $\sigma$ also measures the relative risk aversion.

2 The Frisch elasticity of labour supply measures the response in hours of a wage change when marginal utility of consumption is kept fixed. Thus, it measures the substitution effect of a wage change.

3 Independent and identically distributed. 
not hold any domestic bonds, so when aggregating the budget constraint , the net supply of domestic bonds is zero. The aggregate budget constraint then reads

$$
C_{t}+\frac{S_{t} B_{t}^{f}}{\left(1+r_{t}^{f}\right) \Phi\left(A_{t}\right) P_{t}}=\frac{S_{t} B_{t-1}^{f}}{P_{t}}+\frac{W_{t}}{P_{t}} N_{t}+X_{t}-T_{t} .
$$

Substituting it for the production function, real profits

$$
X_{t}=\left(\frac{P_{H, t}}{P_{t}}-\frac{W_{t}}{P_{t} Z_{t}^{Y}}\right)\left(C_{H, t}+C_{H, t}^{f}\right)+\left(\frac{P_{F, t}}{P_{t}}-\frac{S_{t} P_{F, t}^{f}}{P_{t}}\right) C_{F, t}
$$

and the market clearing condition on the market for domestic goods

$$
Y_{t}=C_{H, t}+C_{H, t}^{f}+G_{t},
$$

is obtained

$$
\frac{S_{t} B_{t}^{f}}{\left(1+r_{t}^{f}\right) \Phi\left(A_{t}\right)}-S_{t} B_{t-1}^{f}=P_{H, t} C_{H, t}^{f}-S_{t} P_{F, t}^{f} C_{F, t} .
$$

The change in net foreign bond holdings is equal to net profits in foreign trade. Alternatively, if the domestic country runs a current account surplus, the surplus will be put in foreign bonds.

The government spending, $G$, is only spent on domestic goods. It is financed by a lump sum tax $T$ and it evolves according to

$$
\ln \left(\frac{G_{t}}{G}\right)=\rho^{G} \ln \left(\frac{G_{t-1}}{G}\right)+\varepsilon_{t}^{G}
$$

The central bank follows a simple Taylor rule for interest rate setting

$$
\hat{R}_{t}=\omega_{r} \hat{R}_{t-1}+\left(\frac{1-\omega_{r}}{R}\right)\left[\omega_{\pi} \hat{\pi}_{t}+\omega_{y}\left(\hat{y}_{t}-\hat{y}_{t-1}\right)\right]+\varepsilon_{t}^{G},
$$

where $R$ is the gross interest rate defined as $R=1+r, \omega_{r}$ is the degree of interest rate smoothing, $\omega_{\pi}$ is the weight on current inflation, $\omega_{y}$ is the weight on output growth, and $\varepsilon_{t}^{r}$ is an i.i.d. shock. For a detailed derivation of the SOE model, see the appendix of Alendal (2008). 


\section{Estimation}

The next step is the log-linearisation of the aforementioned equations. This technique is not described in this paper. For details, see Uhlig (1995). Furthermore, the model is rewritten into Dynare in a log-linearised form. It is an open-source add-on which works in Matlab. For more details, see Adjemian (2012). Dynare uses the Bayesian estimation techniques which are described in Koop (2003) or Hamilton (1994). The algorithm which is implemented in Dynare is described very well in Schorfheide (2000) and see Griffoli (2010) for the Dynare manual. Before the estimation, it is necessary to calibrate all the parameters present in this SOE DSGE model. The whole process of estimating DSGE models is described Villaverde (2009) or Pytlarczyk (2007). The final estimated model consists of 12 log-linearised equations.

$$
\begin{aligned}
& \hat{C}_{H, t}=\hat{C}_{t}-\eta \hat{p}_{H, t}, \\
& \hat{C}_{F, t}=\hat{C}_{t}-\eta \hat{p}_{F, t}, \\
& \hat{C}_{H, t}^{f}=\hat{C}_{t}^{f}\left(\hat{p}_{H, t}-\hat{Q}_{t}\right), \\
& \hat{Y}_{t}=\frac{C_{H}}{Y} \hat{C}_{H, t}+\frac{C_{H}^{f}}{Y} \hat{C}_{H, t}^{f}+\frac{G}{Y} \hat{G}_{t}, \\
& \hat{C}_{t}=\frac{h}{(1+h)} \hat{C}_{t-1}+\frac{1}{(1+h)} E_{t} \hat{C}_{t+1}-\frac{(1-h)}{(1+h)} \frac{1}{\sigma}\left(\hat{r}_{t}-E_{t} \hat{\pi}_{t+1}\right), \\
& \hat{C}_{t}=\left(1-\gamma_{C}\right) \hat{C}_{H, t}+\gamma_{C} \hat{C}_{F, t}, \\
& \hat{R}_{t}-\hat{R}_{t}^{f}=E_{t} \hat{Q}_{t+1}-\hat{Q}_{t}+E_{t} \hat{\pi}_{t+1}-E_{t} \hat{\pi}_{t+1}^{f}-\phi A_{t}+Z_{t}^{B}, \\
& \left.\frac{Q \hat{b}_{t}^{f}}{R^{f}}-Q \hat{b}_{t-1}^{f}=p_{H} C_{H}^{f}\left(\hat{p}_{H, t}+\frac{\sigma}{\varphi(1-h)} \hat{C}_{H, t}^{f}\right)-Q \hat{C}_{t}+\frac{\sigma h}{\varphi(1-h)} \hat{C}_{t-1}=\hat{N}_{t}, \hat{C}_{F, t}\right), \\
& \hat{w}_{t},
\end{aligned}
$$




$$
\begin{aligned}
& \hat{\pi}_{t}^{H}=-\frac{\varepsilon_{H}}{\phi_{C_{H 1}}+(1+\beta) \phi_{C_{H 2}}} \hat{\varepsilon}_{H, t}+\frac{\varepsilon_{H}\left(\varepsilon_{H}-1\right)}{\phi_{C_{H 1}}+(1+\beta) \phi_{C_{H 2}}}\left(\hat{w}_{t}-\hat{Z}_{t}^{Y}-\hat{p}_{H, t}\right) \\
& +\frac{\phi_{C_{H 2}}}{\phi_{C_{H 1}}+(1+\beta) \phi_{C_{H 2}}} \hat{\pi}_{t-1}^{H}+\beta \frac{\phi_{C_{H 1}}+\phi_{C_{H 2}}}{\phi_{C_{H 1}}+(1+\beta) \phi_{C_{H 2}}} E_{t} \hat{\pi}_{t+1}^{H}, \\
& \hat{\pi}_{t}^{F}=-\frac{\varepsilon_{F}}{\phi_{C_{F 1}}+(1+\beta) \phi_{C_{F 2}}} \hat{\varepsilon}_{F, t}+\frac{\varepsilon_{F}\left(\varepsilon_{F}-1\right)}{\phi_{C_{F 1}}+(1+\beta) \phi_{C_{F 2}}}\left(\hat{Q}_{t}-\hat{p}_{F, t}\right) \\
& +\frac{\phi_{C_{F 2}}}{\phi_{C_{F 1}}+(1+\beta) \phi_{C_{F 2}}} \hat{\pi}_{t-1}^{H}+\beta \frac{\phi_{C_{F 1}}+\phi_{C_{F 2}}}{\phi_{C_{F 1}}+(1+\beta) \phi_{C_{F 2}}} E_{t} \hat{\pi}_{t+1}^{F}, \\
& \hat{R}_{t}=\omega_{r} \hat{R}_{t-1}-\left(\frac{1-\omega_{r}}{R}\right)\left[\omega_{\pi} \hat{\pi}_{t}+\omega_{y}\left(\hat{y}_{t}-\hat{y}_{t-1}\right)\right]+\varepsilon_{t}^{r} .
\end{aligned}
$$

The model contains six observed time series. The time series used in this estimation are collected either from ARAD (Czech National Bank database) or from the Czech Statistical Office. The series are: the total consumer index $P$, the consumer price index for domestic goods $P_{H}$, the consumer index for imported goods $P_{F}$, the Gross Domestic Product of the Czech Republic $Y$, the real exchange rate $Q$, the nominal wage income per hour $W$, and the short-term (3-month) interest rate $r$. The nominal wages series is used together with the total consumer price index to form a series for real wages. The data series are for the period 2001Q1 - 2012 Q2. Since the model is stationary, we need to transform our data series to remove the trends by taking four lag differences of the two price indexes. Then we get the gross inflation rates $\pi_{H}$ and $\pi_{F}$. To relate them to the percentage deviation from the steady state, which is the variable in the estimated model, 1 is subtracted. Next, the first differences of the log of the GDP and the real wages are used. The reason for these data transformations is twofold. Firstly, the trend is eliminated. Secondly, a better interpretation of the results is guaranteed. A list of the variables and their description is in Table 1. 
Table 1

Variable descriptions

\begin{tabular}{|l|l|l|l|}
\hline Var & Description & Var & Description \\
\hline$C_{t}$ & Total domestic demand & $r_{t}^{f}$ & Foreign interest rate \\
\hline$C_{H, t}$ & Domestic demand for dom. goods & $N_{t}$ & Labour supply \\
\hline$C_{F, t}$ & Domestic demand for imp. goods & $W_{t}$ & Real wage \\
\hline$C_{H, t}^{f}$ & Foreign demand for dom. goods & $X_{t}$ & Real profits \\
\hline$C_{t}^{f}$ & Total foreign demand & $Y_{t}$ & Domestic production (GDP) \\
\hline$P_{t}$ & Consumer price index & $Z_{t}^{Y}$ & Total productivity \\
\hline$P_{H, t}$ & Price on domestic goods & $Z_{t}^{b}$ & Risk premium \\
\hline$P_{F, t}$ & Consumer's price of imp. goods & $\Gamma_{t}$ & Price adjustment costs \\
\hline$P_{F, t}^{f}$ & Importer's price of imp. goods & $G_{t}$ & Government spending \\
\hline$\pi_{t}$ & Inflation in CPI & $\xi_{t}^{y}$ & Productivity shock \\
\hline$\pi_{H, t}$ & Domestic inflation & $\xi_{t}^{C^{f}}$ & Shock to foreign demand \\
\hline$\pi_{F, t}$ & Imported inflation & $\xi_{t}^{r}$ & Monetary policy shock \\
\hline$\pi_{F, t}^{f}$ & Foreign inflation & $\xi_{t}^{r}$ & Foreign monetary policy shock \\
\hline$B_{t}$ & Domestic bond holdings & $\xi_{t}^{b}$ & Shock to risk premium \\
\hline$B_{t}^{f}$ & Foreign bond holdings & & Shock to foreign inflation \\
\hline$S_{t}$ & Nominal exchange rate & $\xi_{t}^{\varepsilon_{H}}$ & Domestic market power shock \\
\hline$Q_{t}$ & Real exchange rate & $\xi_{t}^{G}$ & Imported market power shock \\
\hline$r_{t}$ & Domestic interest rate & & \\
\hline & & Fiscal policy shock \\
\hline
\end{tabular}

Figure 1 shows the time series used for the estimation of the NKPC parameters. 


\section{Figure 1}

Time series
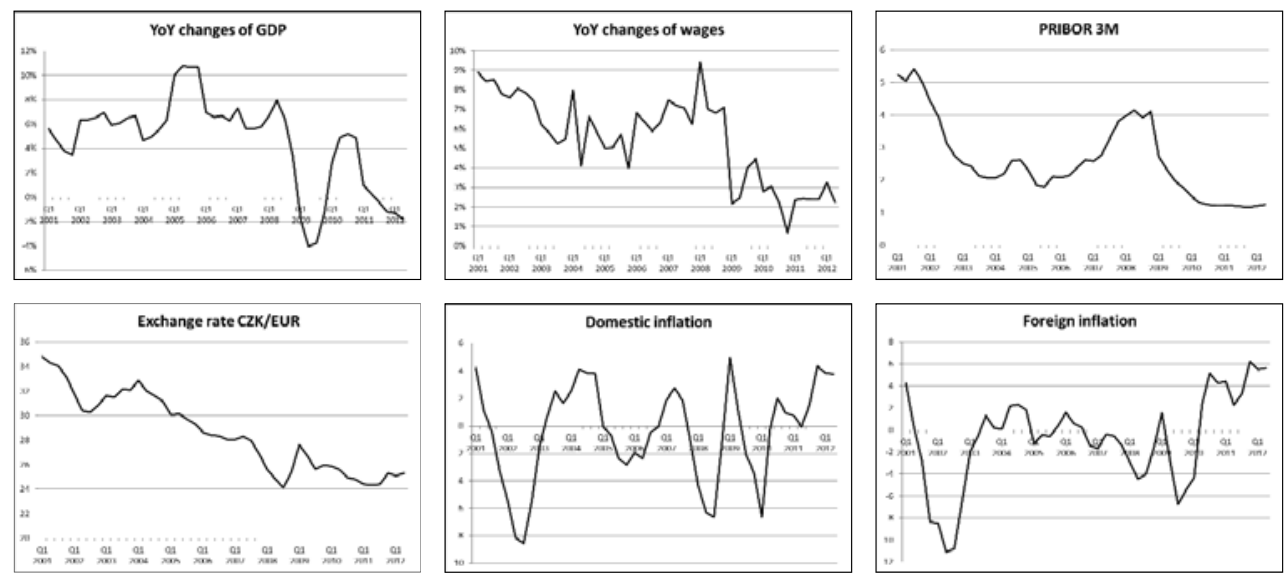

The estimation is focused on the parameters entering the NKPC and the parameters of the shock processes. The calibrated priors of the model are listed in Table 2, as is the description of individual parameters. The DSGE models of the SOE are widely used by financial institutions around the world. The vast majority of the parameters are taken from the previous foreign studies mentioned in Chapter 1.

\section{Table 2}

\section{Calibration}

\begin{tabular}{|l|l|c|}
\hline Parameter & Description & Value \\
\hline$\alpha$ & Degree of openness & 0.32 \\
\hline$\sigma$ & Discount factor & 0.95 \\
\hline$\varphi$ & Intertemporal elasticity of substitution & 1 \\
\hline$\eta$ & Inverse Frisch elasticity of labour supply & 3 \\
\hline$\varepsilon_{H}$ & Elasticity of substitution between domestic and foreign goods & 1.1 \\
\hline$\varepsilon_{F}$ & Elasticity of subst. between different types of domestic goods & 2 \\
\hline$\omega_{\pi}$ & Elasticity of subst. between different types of foreign goods & 6 \\
\hline$\omega_{y}$ & Weight on inflation gap in Taylor rule & 1.5 \\
\hline$\omega_{r}$ & Weight on output gap in Taylor rule & 0.5 \\
\hline$\phi$ & Degree of interest rate smoothing in Taylor rule & 0.7 \\
\hline$h$ & Parameter for risk premium on holding foreign bonds & 0.0002 \\
\hline
\end{tabular}


The priors of the parameters, standard errors and persistence of shocks are in Table 3 . The model contains: a productivity shock, a monetary policy shock, a shock to government spending, shocks in market power for the two types of producers and, finally, a shock to the risk premium on holding foreign bonds. These stochastic shocks attempt to shift the model, which is in the steady state, into a different steady state. The inverse gamma distribution is used for all the standard errors. The beta distribution is in the interval $\langle 0 ; 1\rangle$ and this distribution is used for all the parameters that represent the persistence. The mean value for these parameters is 0.5 , which is a very careful prior. Table 3 summarises the results, which can be compared with the prior values.

Table 3

Estimation results

\begin{tabular}{|l|l|l|l|l|l|l|c|}
\hline \multicolumn{2}{|l|}{ Parameter } & Description & \multicolumn{2}{|c|}{ Prior distribution } & \multicolumn{3}{c|}{ Posterior distribution } \\
\hline \multicolumn{2}{|l|}{} & Type & Mean & S. D. & Mean & $5 \%$ & $95 \%$ \\
\hline$\phi_{C_{H 1}}$ & Discount factor & Beta pdf & 0.950 & 0.1 & 0.9910 & 0.9681 & 0.9875 \\
\hline$\phi_{C_{H 2}}$ & Cost. prev. period & Inv. gam. & 0.075 & inf. & 0.0088 & 0.0088 & 0.0088 \\
\hline$\phi_{C_{F 1}}$ & Cost. steady state & Inv. gam. & 0.150 & inf. & 0.0177 & 0.0176 & 0.0178 \\
\hline$\phi_{C_{F 2}}$ & Cost. prev. period & Inv. gam. & 0.075 & inf. & 0.0882 & 0.0882 & 0.0882 \\
\hline$\rho_{y}$ & Persistence $Y$ & Beta pdf & 0.5 & 0.2 & 0.4529 & 0.4527 & 0.4531 \\
\hline$\rho_{b}$ & Persistence $b$ & Beta pdf & 0.5 & 0.2 & 0.6095 & 0.6091 & 0.6098 \\
\hline$\rho_{G}$ & Persistence $G$ & Beta pdf & 0.5 & 0.2 & 0.6622 & 0.6619 & 0.6625 \\
\hline$\rho_{\varepsilon_{H}}$ & Persistence $\varepsilon_{H}$ & Beta pdf & 0.5 & 0.2 & 0.4303 & 0.4301 & 0.4304 \\
\hline$\rho_{\varepsilon_{F}}$ & Persistence $\varepsilon_{F}$ & Beta pdf & 0.5 & 0.2 & 0.5042 & 0.5038 & 0.5045 \\
\hline stderr $\xi^{Y}$ & & Inv. gam. & 0.02 & inf. & 0.6234 & 0.6204 & 0.6265 \\
\hline stderr $\xi^{b}$ & & Inv. gam. & 0.01 & inf. & 1.5666 & 1.5645 & 1.5693 \\
\hline stderr $\xi^{G}$ & & Inv. gam. & 0.012 & inf. & 2.1421 & 2.1193 & 2.1635 \\
\hline stderr $\xi^{r}$ & & Inv. gam. & 0.0025 & inf. & 0.3766 & 0.3673 & 0.3853 \\
\hline stderr $\xi^{\varepsilon_{H}}$ & & Inv. gam. & 0.05 & inf. & 1.3115 & 1.3069 & 1.3161 \\
\hline stderr $\xi^{\varepsilon_{F}}$ & & Inv. gam. & 0.05 & inf. & 2.8269 & 2.8243 & 2.8293 \\
\hline
\end{tabular}

The most common note of all the DSGE critics is regarding the sensitivity analysis of the chosen prior values. The posterior distribution is very sharp and it is obvious that 
the choice of the prior value plays a minor role for all the estimated parameters. The data information is much stronger than the information value of the prior. Hence, it is not possible to shift the final estimate with different priors.

\section{Results}

The final form of the Phillips curve is obtained by substituting the estimated parameters into and . In the estimation, the priors are set in such a way that the mode is close to fifty-fifty for the gross coefficients for expected future inflation and lagged inflation. Then, the higher the estimate of the parameters $\phi_{C_{1}}$ and the lower the estimates of the $\phi_{C_{2}}$, the more weight is put on the expected future inflation. It is obvious from Table 3 that there is a lot of weight put on the forward term in the Phillips curves: for both domestic and imported inflation, the curves are 0.75 and 0.54 , respectively. The lag term coefficients are 0.25 and 0.46 for domestic inflation and imported inflation, respectively.

$$
\begin{aligned}
& \hat{\pi}_{t}^{H}=-0.049 \hat{\varepsilon}_{H, t}+0.037\left(\hat{w}_{t}-\hat{Z}_{t}-\hat{p}_{H, t}\right)+0.250 \beta E_{t} \hat{\pi}_{t-1}^{H}+0.746 \beta E_{t} \hat{\pi}_{t+1}^{H}, \\
& \hat{\pi}_{t}^{F}=-0.017 \hat{\varepsilon}_{F, t}+0.040\left(\hat{Q}_{t}-\hat{p}_{F, t}\right)+0.456 \beta E_{t} \hat{\pi}_{t-1}^{F}+0.543 \beta E_{t} \hat{\pi}_{t+1}^{F} .
\end{aligned}
$$

The model contains nine stochastic shocks and the DSGE framework allows us to quantify the contribution of each shock. Figure 2 shows the shock decomposition of the domestic inflation. Subsequently, Figure 3 shows the shock decomposition of the foreign inflation.

\section{Figure 2}

Shock decomposition of the domestic inflation

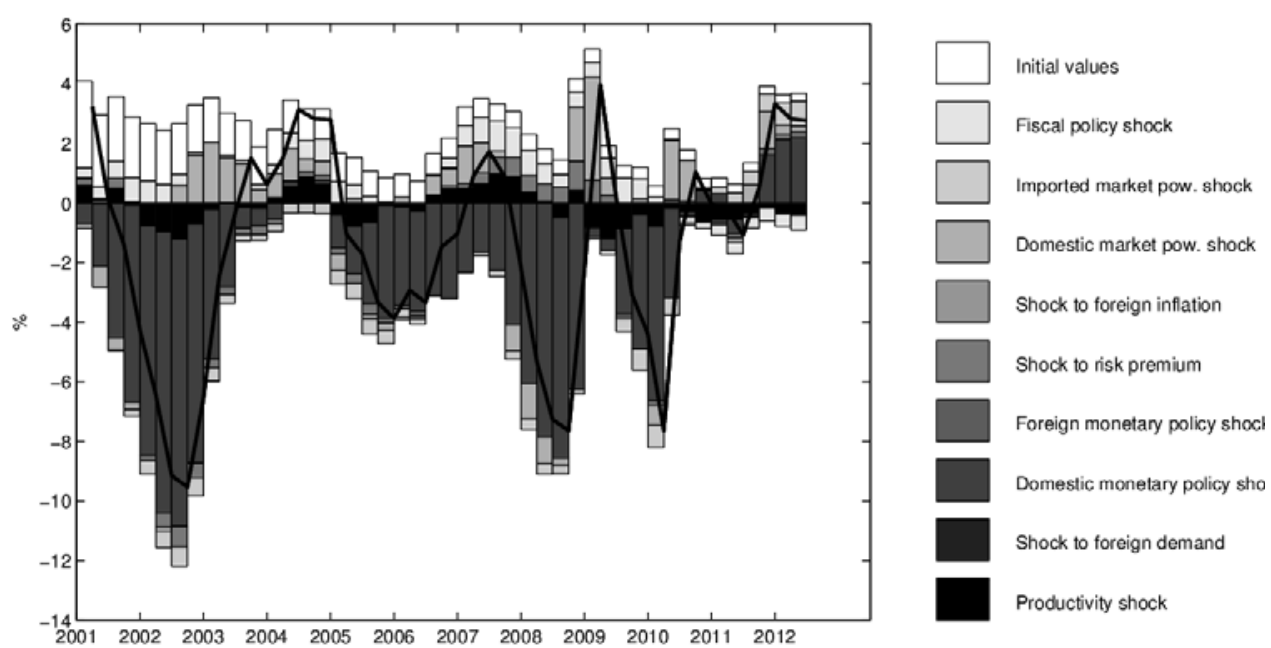


The line shows the time series of the domestic inflation. It is the same time series as the one shown in Figure 1. There are a few periods which indicate a plummeting of the domestic inflation. They are the periods 2002-2003, 2006-2008 and 2010-2011. The main reason for these sudden changes is the domestic monetary policy shock. The other shocks play a minor role. The fiscal policy shock tries to eliminate the domestic monetary policy shock, but the fiscal policy shock is too weak to change anything. Next, the domestic inflation peaks in 2004, 2007, 2008 and 2012. It is mainly caused by the domestic market power shock. This shock is mainly driven by households and their demand for goods. The year 2012 differs from the other years. It is the first time that the domestic monetary policy shock caused domestic inflation to grow.

Figure 3 displays the time series of the imported (foreign) inflation. The domestic monetary policy shock causes the sudden declines and the imported market power shock causes the peaks. There is one phenomenon: the monetary policy shock caused the increase in imported inflation in 2012.

\section{Figure 3}

Shock decomposition of the foreign/imported inflation

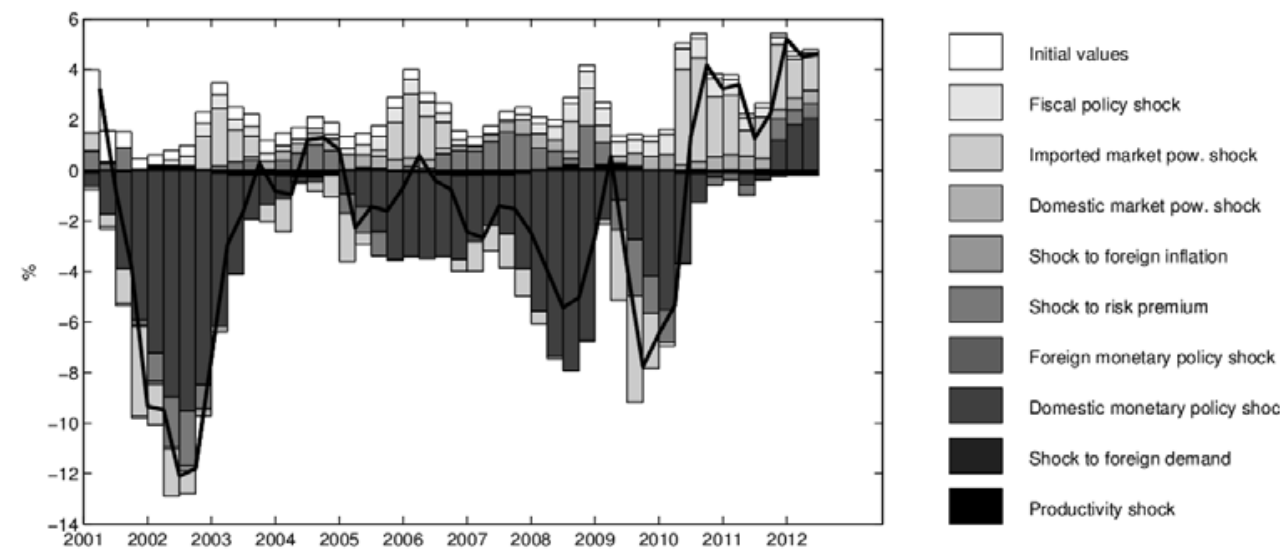

\section{Conclusion}

The paper deals with the estimate of the NKPC, which is formulated and estimated as part of the SOEDSGE model. First, the NKPC history and the past development are described. Subsequently, the NKPC is formulated using previous foreign research. The NKPC of a SOE consists of two equations. The first one represents the domestic inflation and the latter one represents the imported inflation. Moreover, the rest of the SOE model is briefly described. The model contains households, which maximize their utility function using consumption and leisure time, firms, the government and the central bank, which controls the interest rate using the Taylor rule. The third chapter deals with the estimation of the model. In order to estimate the parameters of the NKPC, it is necessary to log-linearise the model and then calibrate all the parameters of the model. Therefore, the DSGE model is fully calibrated. Furthermore, the Bayesian 
techniques are used to estimate the model. The principle of the Bayesian estimation is to join information obtained from data with prior information which is delivered by the analyst. The Czech quarterly data for the period 2001Q1 - 2012Q2 were used for this estimate. The main output of the paper is the estimate of the NKPC parameters. The results show that the expected future inflation plays a dominant role in the NKPC and this finding can be generalised for both domestic and imported inflation. This result seems to be similar to what was obtained by Galí and Gertler (1999), Galí et al. (2001) and Smets and Wouters (2003). Next, a shock decomposition analysis is performed. The shock decomposition quantifies the contribution of each shock to the total level of the observed variable. The main output of this analysis is that the domestic monetary policy shock causes crucial changes in domestic and imported inflation.

\section{References}

ADJEMIAN, S. Dynare: Reference Manual, Version 4 [Dynare Working Papers]. 2012, vol. 1.

ADOLFSON, M.; LASÉEN, S.; LINDÉ, J.; VILLANI, M. Bayesian estimation of an open economy DSGE model with incomplete pass-through. Journal of International Economics. 2007, vol. 72, pp. 481-511.

ALENDAL, L. A. Estimating the New Keynesian Phillips Curve in an Open Economy DSGE Framework [Master Thesis]. Department of Economics. University of Oslo, 2008.

BENIGNO, P. Price Stability with Imperfect Financial Integration [CEPR Discussion Paper]. 2001, no. 2854.

CALVO, G. Staggered Prices in a Utility-Maximizing Framework. Journal of International Economics. 2007, vol. 72, pp. 383-398.

CAMPA, J. M.; GOLDBERG, L. S. Exchange rate pass-through into import prices. The Review of Economics and Statistics. 2005, vol. 87, pp. 679-690.

FUHRER, J. C. The (Un)Importance of Forward-Looking Behavior in Price Specifications. Journal of Money, Credit and Banking.1997, vol. 28, no. 3.

GALÍ, J.; GERTLER, M. Inflation dynamics: A structural econometric analysis. Journal of Monetary Economics.1999, vol. 44, pp. 195-222.

GALÍ, J.; GERTLER, M.; LOPEZ-SALIDO, J. D. European inflation dynamics. European Economic Review. 2001, vol. 45, no. 7, pp. 1237-1270.

GALÍ, J.; MONACELLI, T. Monetary Policy and Exchange Rate Volatility in a Small Open Economy [CEPR Discussion Papers]. 2004, no. 3346.

GOLDBERG, P. K.; KNETTER, M. M. Goods prices and exchange rates: What have we learned? Journal of Economic Literature.1997, vol. 35, pp. 1243-1272.

GRIFFOLI, T. M. Dynare User Guide [online]. 2010 [cit. 2013-03-24]. www.dynare.org/documentation-and-support/manual.

HAMILTON, J. D. Time series analysis. Princeton: Princeton University Press, 1994, xiv, 799 s. ISBN 06-910-4289-6.

HUNT, B.; REBUCCI, A. The US Dollar and the Trade Deficit: What accounts for the late 1990s? International Finance. 2005, vol. 8, no. 3, pp. 399-434.

KOOP, G. Bayesian econometrics. Hoboken, N.J. : J.Wiley, c 2003, xiv, 359 p. ISBN 04-708-4567-8.

PHILLIPS, A. V. The Relation between Unemployment and the Rate of Change of Money Wage Rates in the United Kingdom. Economica. 1958, vol. 25, no. 100, pp. 283-299.

PYTLARCZYK, Ernest. Construction and Bayesian estimation of DSGE models for the EURO area: a statistical framework. Saarbrücken : VDM Verlag Dr. Müller, c 2007, 240 s. ISBN 978-383-6424-806. 
ROTEMBERG, J. J. Sticky Prices in the United States. The Journal of Political Economy. 1982, vol. 90, no.6, pp. 1187-1211.

SCHORFHEIDE, F. Loss Function Based Evaluation of DSGE Models. Journal of Applied Econometrics. 2000 , vol. 15 , no. 6 , pp. 645-670.

SMETS, F; WOUTERS, R. Openness, imperfect exchange rate pass-through and monetary policy. Journal of Monetary Economics. 2002, vol. 49, pp. 947-981.

SMETS, F.; WOUTERS, R. An Estimated Dynamic Stochastic General Equilibrium Model of the Euro area. Journal of the European Economic Association. 2003, vol. 1, no. 5, pp. 1123-1175.

TAYLOR, J. B. Staggered Wage Setting in a Macro Model. American Economic Review. 1979, vol. 69, no. 2, pp. 108-113.

TAYLOR, J. B. Aggregate Dynamics and Staggered Contracts. Journal of Political Economy. 1980, vol. 88 , no. 1 , pp. 1-24.

UHLIG, H.A toolkit for analyzing nonlinear dynamic stochastic models easily [Discussion Paper 1995-97]. Tilburg University, Center for Economic Research, 1995.

VILLAVERDE, J. F. The Econometrics of DSGE models [NBER Working Papers 14677]. Cambridge, 2009.

\section{ESTIMATION OF THE NEW KEYNESIAN PHILLIPS CURVE IN THE CZECH ENVIRONMENT}

Abstract: The paper deals with the estimation of the New Keynesian Phillips curve (NKPC). First, the history of the Phillips curve and the NKPC is outlined. Next, similar research and papers regarding the NKPC are mentioned. The main goal of the paper is to estimate the parameters of the NKPC using the Bayesian techniques. These techniques are widely used for the DSGE model estimation and this paper contains links to the source foreign literature. The NKPC is estimated as part of a fully calibrated Small Open Economy (SOE) DSGE model. The SOE DSGE model consists of households, firms, the government and the central bank. The estimation is performed on the Czech data and the period is from 2001Q1 to 2012Q2. The first output of the paper is the parameter estimates of the NKPC. The main finding is that the future expected inflation plays a crucial role in setting the level of inflation. Moreover, a shock decomposition of domestic and imported inflation is performed and the main output is that the domestic monetary policy shock causes crucial changes in the level of both domestic and imported inflation.

Keywords: New Keynesian Phillips curve, Dynare, Bayesian estimation, Shock decomposition, Small Open Economy

JEL Classification: O47, E17 